Research Article

\title{
Mechanical Properties of Full-Scale Prestressed Concrete Beams with Thin Slab after Exposure to Actual Fire
}

\author{
Chaowei Hao $\mathbb{D}^{1},{ }^{1}$ Yanjiang Chen $\mathbb{D}^{2},{ }^{2}$ Yu Tang, ${ }^{1}$ and Laiyong Wang ${ }^{1}$ \\ ${ }^{1}$ Research Institute of Highway, Ministry of Transport, Beijing 100088, China \\ ${ }^{2}$ Beijing Laboratory of Earthquake Engineering and Structural, Beijing University of Technology, Beijing 100124, China \\ Correspondence should be addressed to Chaowei Hao; cw.hao@rioh.cn
}

Received 20 August 2021; Revised 18 October 2021; Accepted 23 November 2021; Published 10 December 2021

Academic Editor: Antonio Caggiano

Copyright ( 2021 Chaowei Hao et al. This is an open access article distributed under the Creative Commons Attribution License, which permits unrestricted use, distribution, and reproduction in any medium, provided the original work is properly cited.

To provide an effective basis and reference for applications of prestressed concrete thin-slab beams after a bridge fire, methods and principles of fire-resistant design, repair, and reinforcement of such beams were discussed. Taking a simple supported and continuous girder bridge of an expressway in service as a sample, appearance testing and nondestructive testing of the internal structure were carried out. Four representative full-scale prestressed concrete beams were selected. Through the comparative test of the ultimate bearing capacity of such beams, the laws of the deflection deformation, strain distribution, crack formation, and crack development were obtained. By combining with the finite element simulation and theoretical analysis, the ultimate bearing capacity, complex mechanical characteristics, and breakage feature and failure mechanism of such beams were studied. It was indicated by the results the following: (1) Prestress loss will cause height reduction of the concrete shear zone, which is one of the main reasons why the bending-shearing failure of such beams happened before the pure bending failure. (2) Under certain operating loads, brittle fracture is more likely to occur on the bottom surface of such beams when directly exposed to fire. (3) The bursting and spalling depth of concrete after being exposed to fire can be used as the characteristic parameters for the rapid identification of the bottom surface of such after-fire beams.

\section{Introduction}

With the vigorous development of highway traffic in China, more and more inflammable and explosive goods are transported by road and the number of bridge fires is increasing. The fire, which affects the bridges, not only causes economic losses for the country but also brings potential safety hazards to the service of the bridge, affecting the normal operation of the highway. In China, prestressed concrete bridges account for a large proportion of the completed bridges in service [1]. Hollow slab beams are the most common form of medium- and small-span highway bridge superstructures, and about $35 \%$ of concrete girder bridges adopt hollow slab structures [2].

The floor thickness of the hollow slab beam is generally between $8 \mathrm{~cm}$ and $15 \mathrm{~cm}$, which is relatively thin. Once exposed to fire, its effective prestress will decrease, and the overall rigidity of the beam and slab will drop, affecting the normal service of the whole bridge. When conflagration happened, the failure of the complete bonding between steel strand and concrete will lead to structural failure along with the brittle damage of the beam and plate, which will seriously threaten the traffic safety and arouse pernicious social impact. Hence, it is necessary to examine and furtherly study the mechanical properties of those beams from fire-damaged bridges.

Many scholars researched on the mechanical properties of prestressed concrete beams after the fire from different perspectives, including material properties, fire resistance calculation method, evaluation of postdisaster bearing capacity, and new fireproof technologies. Zheng et al. [3] carried out fire resistance tests on 15 prestressed concrete simply supported slabs and 9 two-span unbonded prestressed concrete continuous slabs. The results have shown that concrete spalls more easily when the stress is greater on the surface exposed to fire. Wang et al. [4] have experimented on the creep of high-strength prestressed rebars under high-temperature conditions, establishing a high- 
temperature creep model of those rebars. The necessity of considering the creep of the concrete when analyzing the fire resistance performance of the prestressed concrete structures was verified. Ding et al. [5] studied the temperature field and relaxation of prestressed tendons of concrete beams and slabs through numerical simulation and model tests when underbridge space encountered fire. It turned out that, after the fire, the prestress loss of the steel strands from such beams and slabs has occurred. The higher the fire field temperature, the greater the prestress loss. Based on the investigation of the firing time and its temperature, after-fire prestress loss is analyzed. And the foundation for postdisaster assessment of bridge performance was laid. Dwaikat and Kodur [6] established a monolithic model of highstrength concrete bursting and spalling based on the influence of concrete pore water pressure, pointed out that the axial constraint has an obvious influence on the bursting and spalling performance of concrete beams, and concluded that high-strength concrete has lower fire resistance performance than ordinary concrete due to the effect of its surface concrete bursting and lower permeability. Kodur and Dwaikat [7] studied the influence of the stress-temperature path on the prestressed concrete beams and slabs. A numerical method considered the thermal-mechanical coupling effect that was proposed. By combining with experimental data, the fire resistance performance of prestressed concrete beams and slabs was learned. Yun and Jeon [8] proposed a method to evaluate the fire damage of bridge structures based on the thermal-structure interaction then applied this method to prestressed concrete bridges, respectively. It was founded that the temperature distribution, deflection, and its standard fit well with the standard fire test results. Zhang et al. [9] used the thermal field coupling calculation method to explore the failure mode of T-section prestressed concrete beam bridges under different fire modes. The beam rib and flange plate deformation of such beams were tracked under different fire modes. As for the long-span prestressed concrete box girder bridges (PC box girder bridges). Yanagisawa et al. [10] discovered a method that can identify the failure mode of the after-fire bridge and reduce the fire damage by adding a fire protection panel (FFP). And the effectiveness of the method through real practice was forwardly testified. Taking into account the geometric nonlinearity, material nonlinearity, and nonlinear thermal gradient, and combining the bidirectional coupling between thermal analysis and structural analysis, Prakash and Srivastava [11] proposed a nonlinear thermal analysis method for RC beam fire based on the direct stiffness method. The results show that the framework can predict the response of RC structure well. Alos-Moya et al. [12] calibrated the fire model by using the temperature results of Valencia bridge fire test conducted by Valencia Polytechnic University in Valencia (Spain). The results show that some of the fire stability models are only suitable for scale bridge fire test, not for actual bridge fire analysis. Beneberu and Yazdani [13] carried out a full-scale single-span prestressed concrete bridge that was tested under a combined hydrocarbon fire and simulated AASHTO live load. The results show that without fire prevention measures, the carbon fiber cloth will degum rapidly, resulting in serious spalling of concrete and loss of some prestressed steel strands. Kodur et al. [14] studied the fire resistance of composite box girder with transverse and longitudinal stiffeners and proposed a method to predict the failure time of arch bending moment zone of continuous composite box girder based on deflection ratio. The results show that the fire resistance of continuous composite box girder can be significantly improved by preventing the negative bending moment zone of continuous composite box girder from fire.

As mentioned above, the studies about the mechanical properties of prestressed concrete girder bridges after the fire were mainly focused on five aspects, including material properties, thermal performance, effective prestress loss mechanism, fire resistance performance tests of reducedscale components, and numerical simulation analysis of the entire bridge. However, research based on the mechanical properties of full-scale beams after the fire is still lacking. After experiencing different high-temperature burning, the failure criteria and morphology of prestressed concrete thinslab beams have not been studied in depth. In this paper, to obtain the law of deformation, strain, and crack development, a full-scale failure test of such beams is carried out. Combined with theoretical and numerical analysis, several properties are studied, including the ultimate bearing capacity, force characteristics, and failure mechanism of such beams. These results can serve as a decision-making foundation for the practical fire-resistant design, maintenance, and reinforcement of similar beams.

\section{Method}

2.1. Source and Classification of Test Components. A precast $9 \times 20 \mathrm{~m}$ prestressed concrete hollow bridge in-service on provincial expressway is designed in split width, and each width contains 16 hollow slab beams [15]. The minimum floor thickness of this bridge is $15 \mathrm{~cm}$, the net protection layer thickness of steel strands is $3.6 \mathrm{~cm}$, and the designed value of standard cube compressive strength of concrete is $50 \mathrm{MPa}$. Each middle beam of this bridge is equipped with 14 steel strands, and the effective length of these steel strands is shown in Table 1. Each prestressed steel bundle is composed of $6 \times \Phi$ s 15.2, whose standard tensile strength of prestressing tendons is $1860 \mathrm{MPa}$ and the tension control stress is $1395 \mathrm{MPa}$. The reinforcement of elevation and middle plate are shown in Figure 1.

All reliable samples in this study come from the hollow slab removed from the bridge above after exposure to fire due to the oil tank truck at its bottom. The tank truck rolled over under the sixth hole of that bridge, causing the fuel tank to rupture and burn. The fuel flowed along the road to the seventh hole and then burned a large area. As a result, the bottom surface of the girder slab near the 6th and 7th holes was directly burned by the fire nearly two hours (the side face was not directly overfired).

According to the appearance test results, the web of the hollow slab girder was not directly burned by the fire source, suffering little influence on the shear bearing capacity. Thus, little web plate damage was found. In addition, after multiple 
TABLE 1: Effective length of strand (unit: $\mathrm{m}$ )

\begin{tabular}{lcccccc}
\hline No. & 1 & 2 & 3 & 4 & 5 & 6 \\
\hline L & 19.9 & 16.8 & 15.2 & 13.2 & 11.0 & 7.8 \\
\hline
\end{tabular}

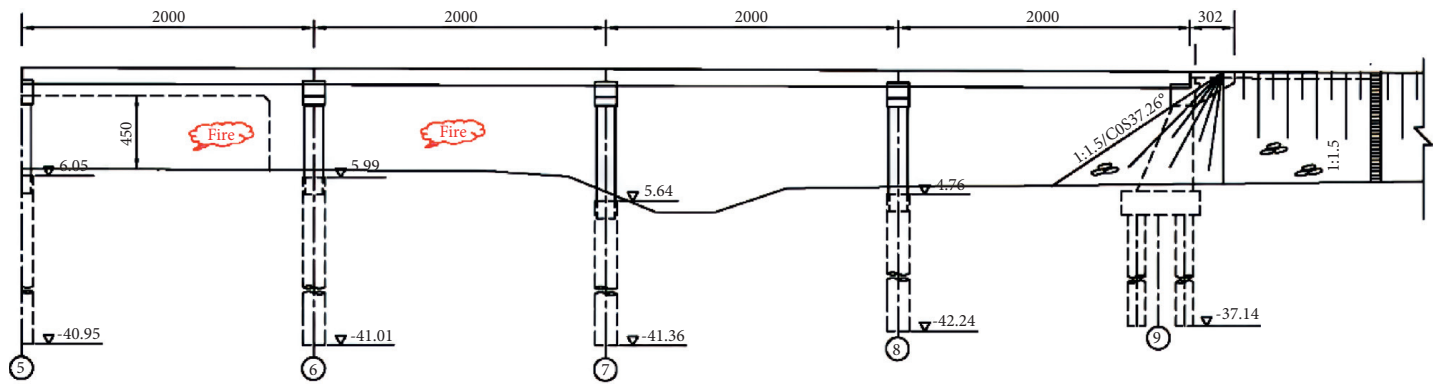

(a)

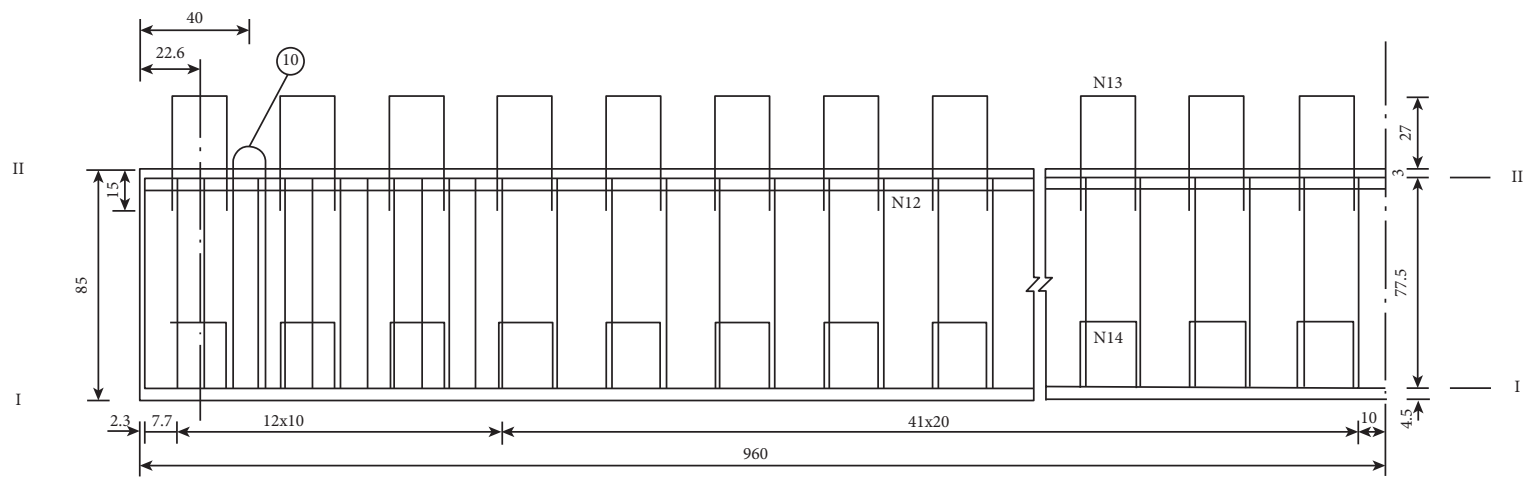

(b)

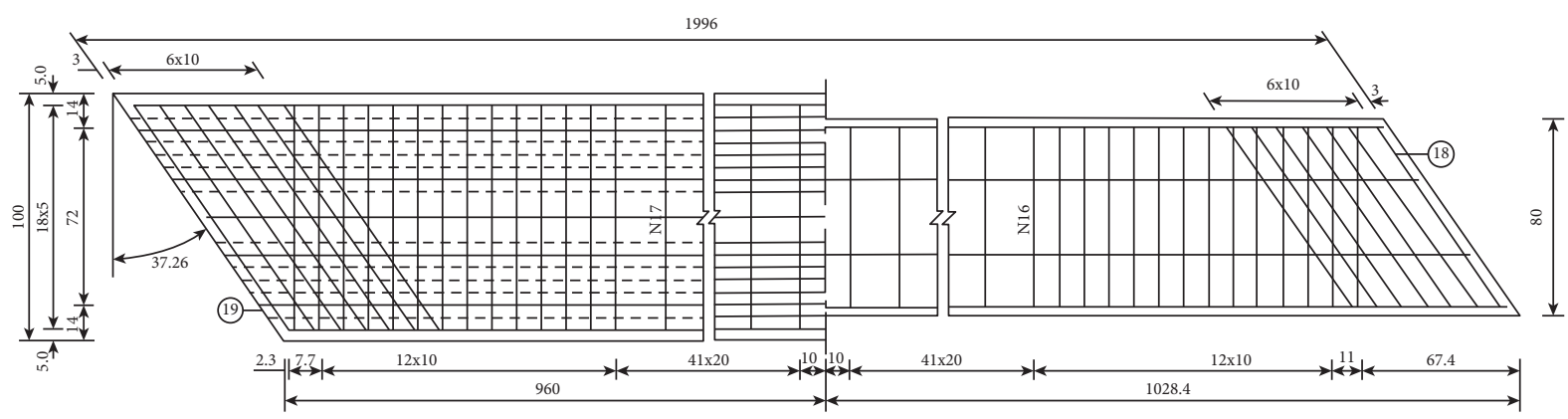

(c)

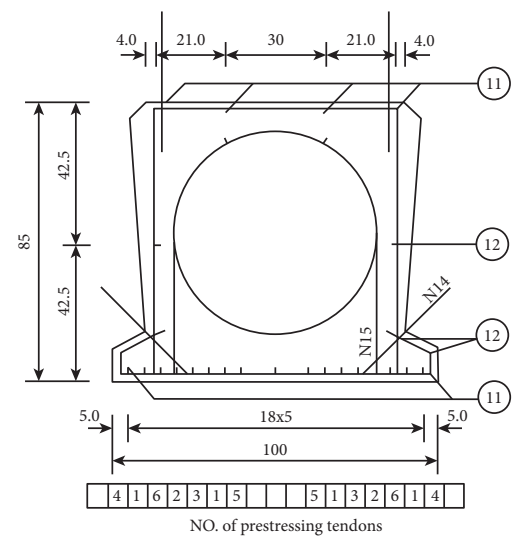

(d)

FIgUre 1: The elevation and reinforcement diagram. (a) Elevation (the unit of elevation is $\mathrm{m}$, and the unit of span is $\mathrm{cm}$ ). (b) Medium plate reinforcement diagram. 
hoisting and transportation, most of the beams and slabs have varying degrees of damage near the fulcrum. Therefore, it is very important to carry out the bending bearing capacity test, which is our main test. The hollow slabs are divided into four categories differentiated by the degree of after-fire damage for the later experiment. See Table 2 and Figure 2. Among them, beam 2\# is the reference beam, which is nearly unaffected by the fire. The proving process will be discussed in Section 3 as follows, through numerical simulation and experimental comparison of these beams.

2.2. Loading Device. Loading devices include ultra-highpressure jack, rubber-bearing, welded H-type steel beam and counterforce beam, number display pressure ring, Ф32 fine-rolled rebar, and gravity ground anchor device. The pressure generated by the jack is applied to the longitudinal loading beam in the form of a reaction force through the ground anchor device. Then, the force is transferred from the longitudinal beam to the hollow slab structure through a rubber bearing (steel pad). The maximum bending moment in the normal section and the maximum shear force from one-third to two-thirds of the span length has been considered simultaneously in the test loading arrangement. The loading arrangement layout is detailed in Figure 3, and the on-site loading situation is shown in Figure 4 .

2.3. Process of the Loading Test. The test of each beam is divided into two loading conditions. The first condition means loading until each cross section reaches or is close to the design value of an ultimate bending moment, and the second condition means loading to the actual ultimate failure state or the loading to the test termination conditions. The loading process is shown in Table 3. Refer to the relevant specifications for test termination conditions.

\subsection{Items and Methods for the Test}

2.4.1. Beam Deflection and Pier Settlement Measurement. The deflection of the beam and the test bench under various loading conditions is measured by using AL-ML32 highprecision leveling instrument shown in Figure 5. Numbers of deflection and settlement at one-quarter of the span length, three-quarters of the span length, and the midspan can be read through the preembedded indium steel ruler.

2.4.2. Strain Measurement of the Key Sections. On both sides of the hollow slab beams, along the height direction of the webs, bridge strain gauges were arranged for measurement, especially at one quarter, three quarters, one-eighth, threeeighths of the span length, and the midspan.

The detailed arrangement of measuring points is shown in Figure 6.

2.4.3. Crack Observation and Damage Pattern Recording. Before the test, the initial conditions of the selected beams were carefully checked, the original cracks were marked, and the original crack diagram was drawn in detail. The two sides of the hollow slab girder web are divided into $20 \mathrm{~cm}$ square grids at equal intervals as the reference coordinate system for recording cracks on the concrete surface. During the test, the appearing cracks were drawn on the beam and recorded, and the corresponding load size when the cracks appeared was marked. At the same time, several representative cracks were selected to track and measure their width changes.

2.5. Numerical Simulation. According to Chaowei et al. [15], after obtaining the material's mechanical performance parameters, the ultimate bearing capacity of the prestressed concrete beam was analyzed. And the finite element analysis method was applied during this process to meet the required engineering accuracy. The comparison between numerical simulation and the experiment proves that the beam $2 \#$ is almost unaffected by the fire and thus can be used as the reference beam [15]. The general large-scale finite element software ANSYS is used for modeling. SOLID65 elements should be selected for concrete. The stress-strain relationship model of concrete is an important part of the nonlinear analysis of after-fire concrete hollow slabs. And the dynamic hardening model is used for this simulation. In the concrete failure criterion, the sheartransfer coefficient of open cracks is set to 0.7 after trial calculations based on relevant experience, and the sheartransfer coefficient of closed cracks is set to 0.95 . The uniaxial stress-strain of concrete can be found in [15]. Steel strands are simulated by the LINK8 unit, without considering the bond-slip between steel and concrete, and steel strands are simulated by the bilinear isotropic strengthening model BISO considering strengthening. To consider the exact effects, ordinary steel bars are dispersed into concrete elements in a way of defining real constants (reinforcement ratios of stirrups and longitudinal and transverse steel bars). In order to prevent stress concentration from causing the in-advance jumping out of the calculation, a unit with an elastic modulus 100 times that of concrete is set at the loading position and the bridge bearing. When dividing elements, a hexahedral mapping grid is used. The number of bridge elements is 5918 in total, and the number of nodes is 8266 . The finite element model is shown in Figure 7.

\section{Result and Discussion}

Due to the requirements for keeping the bridge appearance and the nondestructive inspection in the early stage, the test bench bed has a clear height of $1.2 \mathrm{~m}$. Because of the safety considerations and limited working stroke of the jack, the loading test stopped in advance before the hollow slab beam was completely destroyed. So, there was no complete destruction of the structure, such as concrete crushing, beam fracture, and beam slab collapse. The main reaction of the structure during the test was learned: (1) As the load increases, the deflection of the beam continues to increase, and deformation 
TABLE 2: The appearance of test beam.

\begin{tabular}{|c|c|}
\hline No. & ppearance of the floor (the floor is divided into 70 areas) \\
\hline 2\# & ncrete was fumigated and blackened in partial areas without any other \\
\hline 3\# & $\begin{array}{l}\text { The color of the concrete remains unchanged. The sound of hammering in } 6 \% \text { of the concrete area is dull. } 30 \% \text { of the concrete area } \\
\text { falls off with a characteristic depth of } 2.1 \mathrm{~cm} \text {, mostly locating at the end of the beam. And a small part of the beam-end steel strand is } \\
\text { exposed, distributed from the fulcrum to quarter of the span }\end{array}$ \\
\hline 4\# & $\begin{array}{l}6 \% \text { of the concrete area is pink. Micro-crack and coarse-crack networks appear in partial areas. The sound of hammering in } 76 \% \text { of the } \\
\text { concrete area is dull. } 97 \% \text { of the concrete area falls off with a characteristic depth of } 2.6 \mathrm{~cm} \text {. And the steel strands are exposed in some } \\
\text { areas }\end{array}$ \\
\hline 5\# & $\begin{array}{l}98 \% \text { of the concrete area is pink or khaki. The sound of hammering in } 96 \% \text { of the concrete area is dull. } 100 \% \text { of the concrete area falls } \\
\text { off with a characteristic depth of } 3.6 \mathrm{~cm} \text {. And steel strands in } 25 \% \text { of the concrete area have been exposed, which distributes from the } \\
\text { fulcrum to a half of the span }\end{array}$ \\
\hline
\end{tabular}

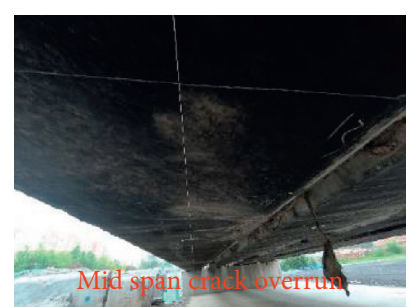

(a)

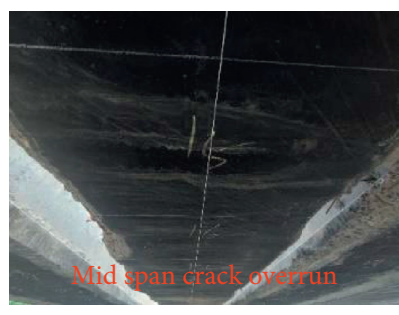

(b)

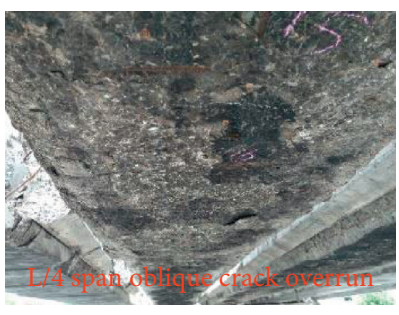

(c)

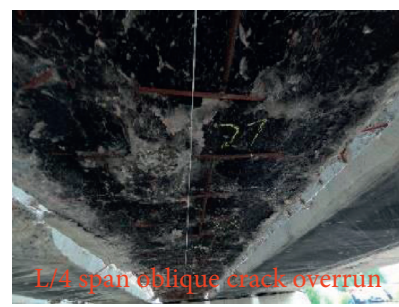

(d)

Figure 2: The appearance of test beam. (a) No. 2\#. (b) No. 3\#. (c) No. 4\#. (d) No. 5\#.

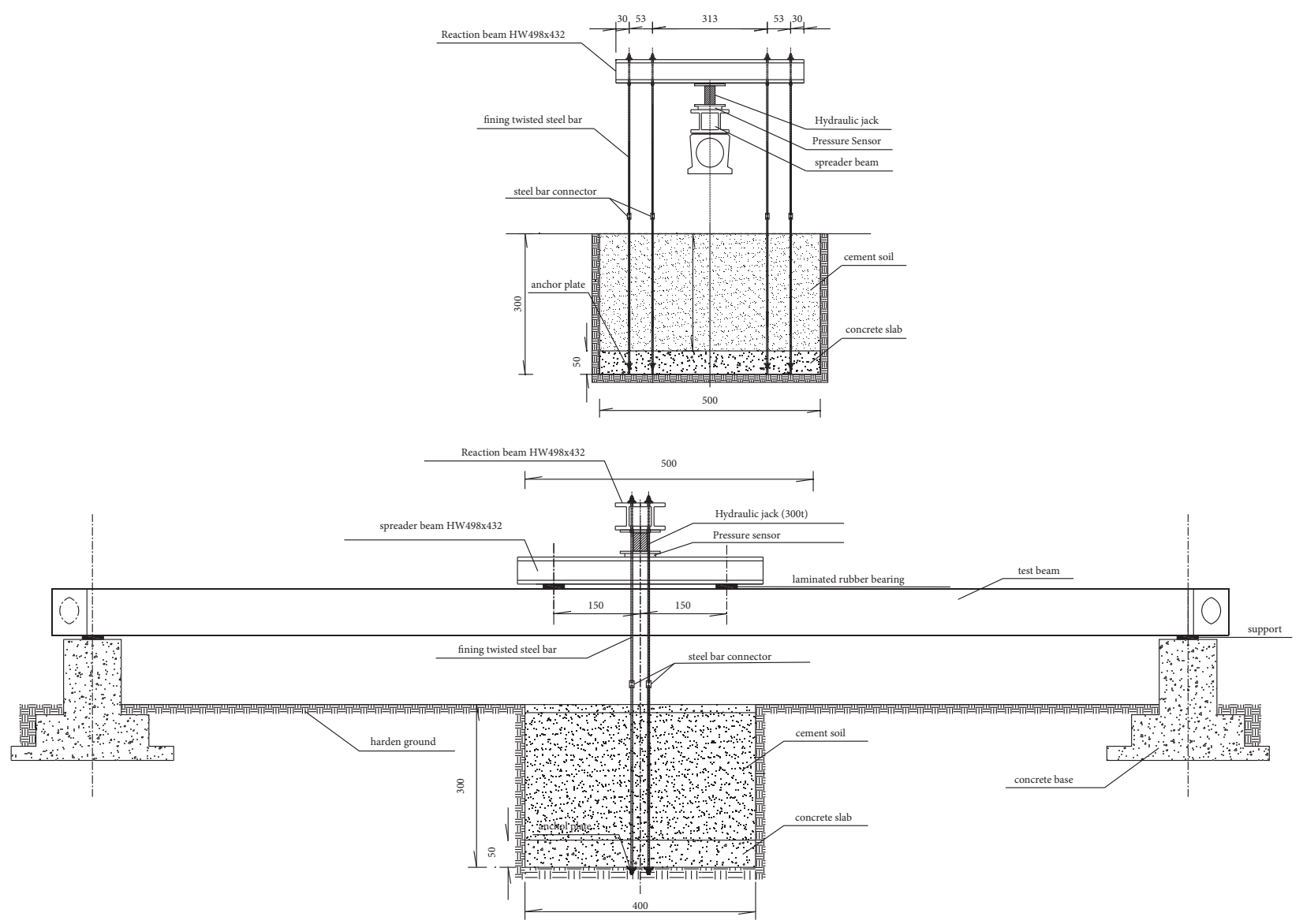

FIgURE 3: The loading arrangement (unit: $\mathrm{cm}$ ). 


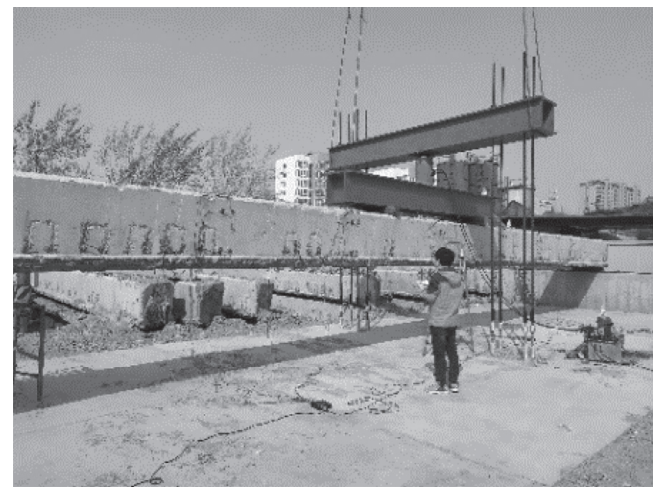

FIgURE 4: The on-site loading situation.

TABLE 3: Loading process for hollow slab beams.

Step Description

1 Deadweight (including distributing beam and jack deadweight). The load will last for 15 minutes to eliminate the inelastic deformation of the beam end support

Preload, load directly to $30 \%$ of the calculated ultimate load, last for 5 minutes, and then unload to zero. Force-control mode is adopted. The main purpose is to further eliminate the inelastic deformation of the loading system and verify the reliability of the loading system

Under formal loading, the ultimate load of hollow slab beams is calculated by 10 stages, and the ultimate load of hollow slab beams is calculated by $10 \%$ for each stage. Each step loading lasts for 5 minutes and force-control mode will be adopted.

After $100 \%$ ultimate load, unloading is carried out, and then four stages of secondary loading to $100 \%$. Finally, the hollow slab beam is destroyed by intensive loading. The ultimate load of each stage is calculated by $5 \%$ ultimate load. Each step loading lasts for 5 minutes and force-control mode will be adopted

5 If the deformation of all hollow slab beams cannot converge with time, that is, the deformation cannot stop, it means that they have entered the ultimate load-bearing state, immediately stop loading, record the corresponding data and unload

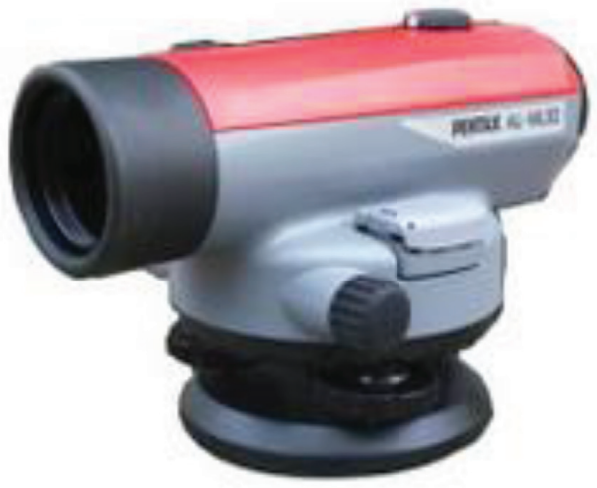

FIgURE 5: The AL-ML32 high-precision leveling instrument.

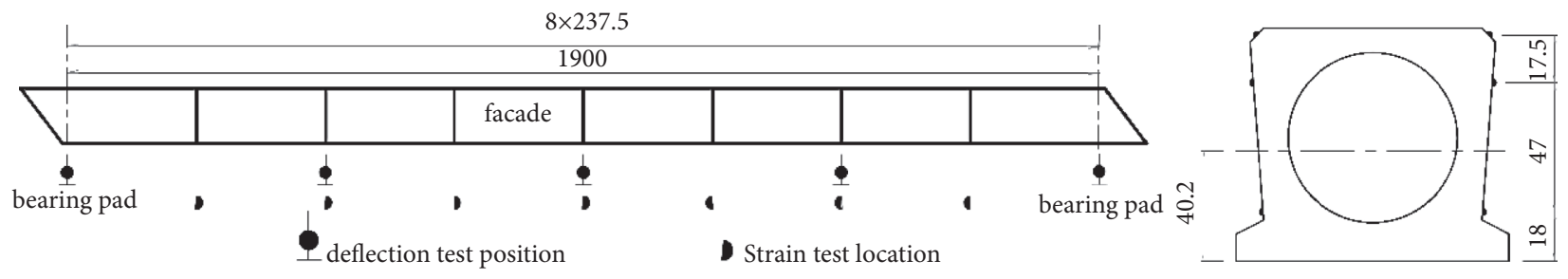

Figure 6: The strain location and deflection measuring points. 

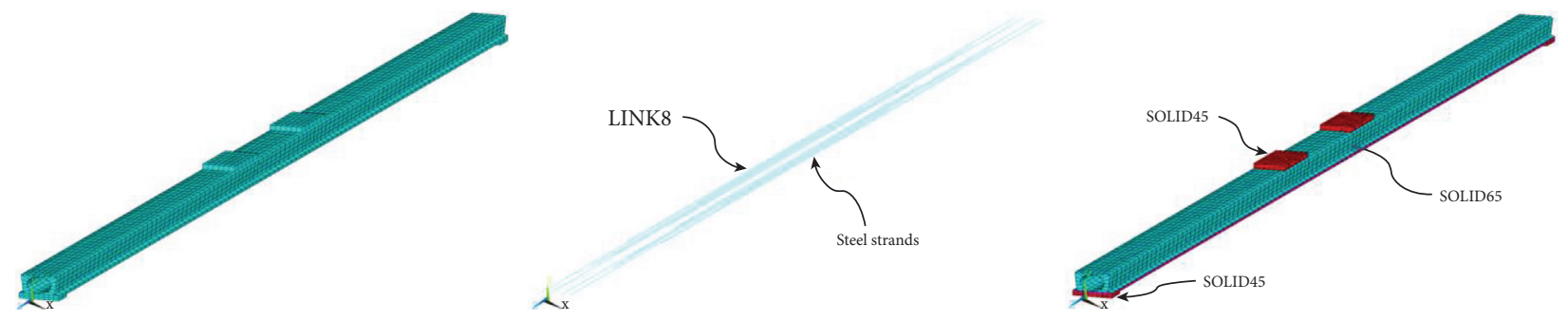

Figure 7: Finite element model.

gradually develops from linear to nonlinear when the total load is greater than 16 tons. (2) The original cracks gradually widened, and the area where new cracks first appeared was within $5 \mathrm{~m}$ of the longitudinal distance from the midspan and gradually extended toward the fulcrum as the loading progressed. The average crack spacing gradually decreased when load increases.

Cracks were spotted at the midspan where the longitudinal distance is $5.5 \mathrm{~m}$. When these oblique cracks at the oblique cracks at the main tendon under tension firstly exceeded the vertical width of $1.5 \mathrm{~mm}$, the loading was stopped. Typical failure mode is shown in Figure 8 and Table 4. It can be seen from the table that as the degree of beam damage increases, the failure mode of the test beam changes; that is, the shear failure will occur before the pure bending failure. The main reason was founded after careful considerations. As the fire temperature increases, the effective prestress of the bottom plate at one-quarter of the span length will decrease gradually, and the axial pressure that prevents the appearance and development of oblique cracks will decrease. Besides, due to the reduced strength of steel strands and concrete materials, the damage mode of such beams finally changes.

\section{Analysis}

\subsection{Analysis of the Displacement}

4.1.1. Normal Loaded Displacement. The normal-loaded deflection-load curve of midspan is shown in Figure 9. From the figure, the displacement-load relationship of the beam 2\#, beam 3\#, and beam $4 \#$ is linear when the total load distributes from 0 to 16 tons (just call it " $0-16 t$ stage" in the following passage). The displacement-load of the beam $4 \#$ in the " $0-8 t$ stage" is linear. In the "15 32t" stage, the measured stiffness of the hollow slab beam $2 \#, 3 \#$, and $4 \#$ has decreased, and the downward deflection value of the midspan has accelerated. In the " $5 \sim 32 t$ " stage, the stiffness of the hollow slab beam $4 \#$ has decreased. While before the " $5 t$ stage," the reduction of the stiffness was obvious but not too sharp during the loading process.

After the fire of hollow slab beams, due to the appearance and development of microcracks or cracks, as well as the loss of the prestress, the structural rigidity of the hollow slab section will be degraded. This phenomenon is defined as the stiffness degradation for convenience. By comparing this stiffness degradation, the precise performances of those 4 beams will be learned. The hollow slab beam $2 \#$ is basically not affected by the fire and thus can be used as our benchmark for the stiffness. Under the same level of load, the deflection ratio of the remaining beams to the beam $2 \#$ is defined as the relative after-fire degradation stiffness $K_{f}$, and the calculation formula is shown as follows:

$$
K_{f}=\frac{\delta_{0}}{\delta_{i}},
$$

where $\delta_{0}$ is midspan deflection of the unfired beam and $\delta_{i}$ is midspan deflection of beam $i \#$ under the same load.

When the maximum total load under normal loading is $32 t$, it can be seen from Table 5 that the maximum bending moment of the corresponding pure bending section in the midspan is $1906 \mathrm{kN} \mathrm{m}$, which has reached the design limit. It is calculated using the material-design values for calculation, according to the regulation "JTJ D62-2004 Code for Design of Highway Reinforced Concrete and Prestressed Concrete Bridges and Culverts" [16]. The relative after-fire degradation stiffness $K_{f}$ of beams 3\#, 4\#, and $5 \#$ is, respectively, $89.4 \%, 81.5 \%$, and $76.1 \%$. Since those four selected beams were originally located in two adjacent holes of the same bridge, the stiffness of the 4 beams before the fire can be considered equal, and the mass distribution of those beams after the fire is supposed to be unchanged. The $K_{f}$ value is consistent with the 3, 4, 5 boundaries of the bridge natural frequency assessment scale, which is from the regulations called "JGJ/T J21-2011, Specification for inspection and evaluation of the load-bearing capacity of highway brides" [17], which means that the test of those four beams is very typical.

The mechanical properties of concrete and steel reinforcement materials will decrease to varying degrees after a bridge fire. When the overfire temperature exceeds $300^{\circ} \mathrm{C}$, the elastic modulus $(E)$ of the concrete after natural cooling is only 0.75 times that before the overfire. The higher the overfire temperature, the greater the reduction coefficient of elastic modulus. When the overfire temperature exceeds $800^{\circ} \mathrm{C}$, the reduction coefficient of concrete elastic modulus after natural cooling is only 0.03 . Fire will cause the elastic modulus of the steel bar to decrease after cooling, but its reduction coefficient is less than that of concrete under the same overfire temperature. And that coefficient is 0.9 when the overfire temperature is $400^{\circ} \mathrm{C}$. Although the elastic modulus of the steel strand is hardly reduced after the fire, 


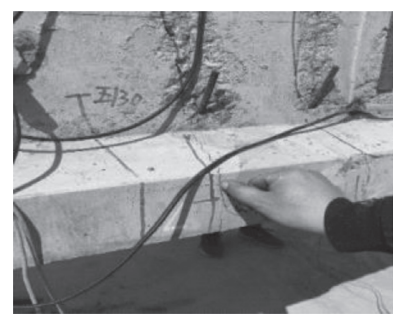

(a)

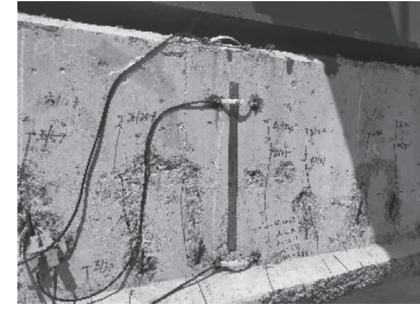

(b)

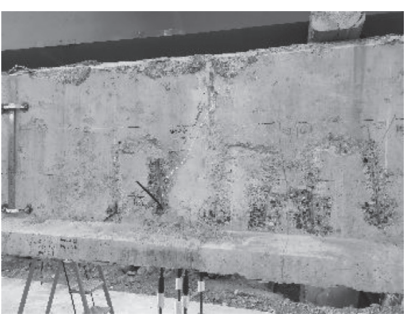

(c)

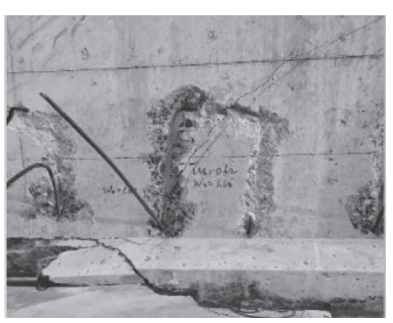

(d)

Figure 8: The typical failure pattern. (a) No. 2\#. (b) No. 3\#. (c) No. 4\#. (d) No. 5\#.

TABLE 4: The failure mode of test beams.

\begin{tabular}{ll}
\hline Beam no. & Failure form \\
\hline $2 \#$ & The cracks in the tensioned main steel bars near the middle of the span first exceed the width of $1 \mathrm{~mm}$ \\
$3 \#$ & The cracks in the tensioned main steel bars near the middle of the span first exceed the width of $1 \mathrm{~mm}$ \\
$4 \#$ & The width of the crack at the tensioned main steel bar at the diagonal crack near $6.5 \mathrm{~m}$ from the middle span exceeds $1 \mathrm{~mm}$ \\
$5 \#$ & The width of the crack at the tensioned main steel bar at the diagonal crack near $5.5 \mathrm{~m}$ from the middle span exceeds $1 \mathrm{~mm}$ \\
\hline
\end{tabular}

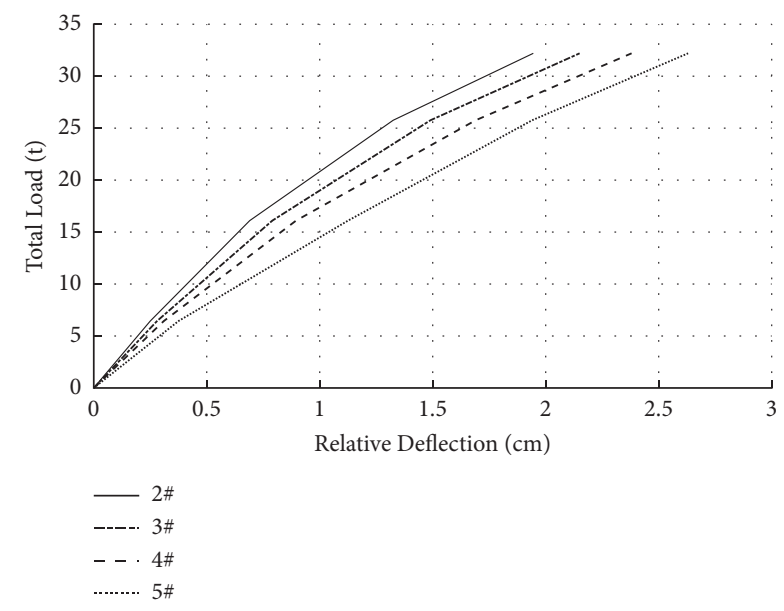

FIgURE 9: Midspan deflection-load curve of normal loading.

the effective prestress of the steel strand will decrease anyway, which will cause the overall rigidity of the beam to decrease too. As a result, when the fire temperature increases, the stiffness of the bridge after cooling decreases gradually.

\subsubsection{Displacement under Ultimate Loading Condition.} The ultimate load results are summarized in Table 6 and Figure 10. From the table, the ultimate bending moments of beams $2 \#, 3 \#, 4 \#$, and 5\# are reduced successively. And the ultimate bending moment of beam $5 \#$ is only $76.4 \%$ compared to beams not exposed to fire, which is reduced by $23.6 \%$. The corresponding deflection values of the limit bending moment of beams $2 \#, 3 \#, 4 \#$, and $5 \#$ are gradually increased. Consequently, as the fire damage becomes more and more serious, the ultimate damage mode gradually changes from ductile failure to brittle failure, especially for beam $5 \#$. The ultimate failure deflection of beam $5 \#$ after the fire is only $28.5 \%$ of that before the fire.
TABLE 5: Maximum deflection and relative overfire degradation stiffness in midspan under normal loading.

\begin{tabular}{lcc}
\hline Beam no. & Maximum deflection $(\mathrm{cm})$ & Relative stiffness $/ K_{f}(\%)$ \\
\hline $2 \#$ & 1.94 & 100.0 \\
$3 \#$ & 2.17 & 89.4 \\
$4 \#$ & 2.38 & 81.5 \\
$5 \#$ & 2.65 & 76.1 \\
\hline
\end{tabular}

TABLe 6: Limit loading displacement results.

\begin{tabular}{lcccc}
\hline Beam no. & 2\# & 3\# & 4\# & 5\# \\
\hline Total loading weight $(t)$ & 69.7 & 65.1 & 63.7 & 49.4 \\
Limit moment $(\mathrm{kN} \cdot \mathrm{m})$ & 3429 & 3247 & 3191 & 2619 \\
Relative value of the unburned & 100 & 94.7 & 93.1 & 76.4 \\
beam (\%) & & & & \\
Limit midspan deflection $(\mathrm{cm})$ & 37.2 & 26.55 & 15.95 & 10.62 \\
\hline
\end{tabular}

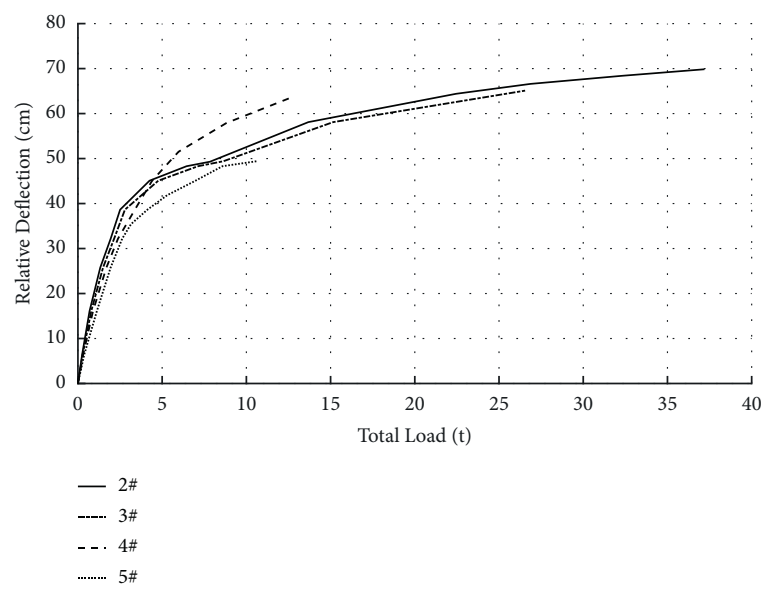

Figure 10: Deflection-load curves of beam 2\# and beam $5 \#$ in midspan.

Figure 11 is the contrast diagram of finite element simulation values between beam $2 \#$ and the unfired beam. The midspan deflection of beam $2 \#$ was almost equal to the 


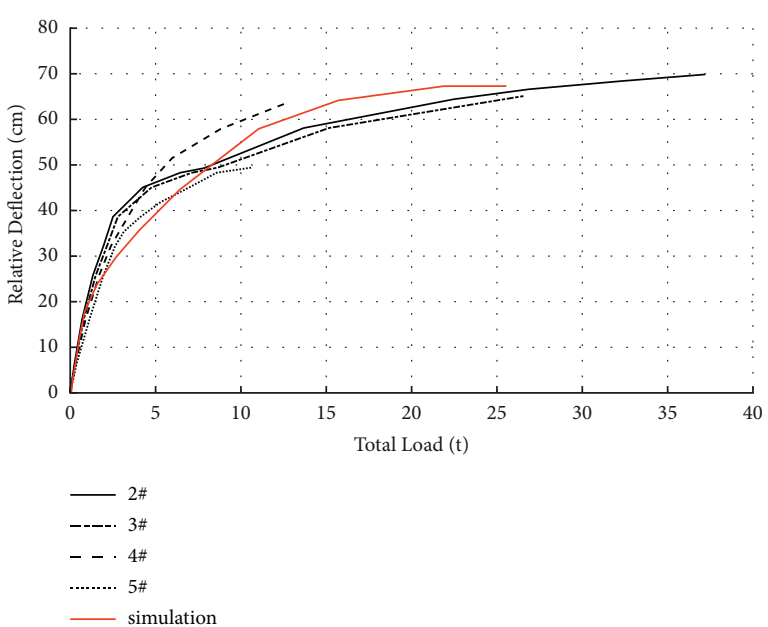

Figure 11: Contrast diagram of midspan deflection (simulated value of beam $2 \#$ and the unfired beam).

simulated value before cracking. And there is only a slight difference of the deflection before and after cracking, which can furtherly prove that beam $2 \#$ is unaffected by the fire and can be used as the reference beam. The mechanical properties of concrete and steel reinforcement materials will decrease to varying degrees after a bridge fire. The reduction coefficient of concrete compressive strength after natural cooling is only 0.8 times of the strength before the fire, when the overfire temperature exceeds $300^{\circ} \mathrm{C}[18,19]$. The strength reduction coefficient grows when the overfire temperature increases. And that coefficient reaches 0.2 under an overfire temperature beyond $800^{\circ} \mathrm{C}$. Fire will cause the yield strength of the steel bar to decrease after cooling, but its reduction coefficient is less than that of concrete under the same overfire temperature. And that coefficient is 0.95 at around $400^{\circ} \mathrm{C}$ (which is the overfire temperature). After high temperature, the yield strength of prestressed steel bars has a certain relationship with the highest temperature and the initial stress level [20]. The ultimate strength and yield strength generally decrease with the increase of temperature. Also, the fire not only causes the physical properties of steel bars and steel strands to decrease, but also reduces the bonding force between them and its wrapping concrete [21]. As the overfire temperature increases, the concrete spalling becomes more serious, and the effective stress of the steel strands is distributed more unevenly along the longitudinal direction [22,23]. With the gradual increase of the load, this phenomenon becomes far more obvious, which will cause the steel bar (steel strand) to yield before the concrete compression crashing. And the phenomenon is quite similar to the failure of underreinforced beams. The following test results of full-scale compressive strain and diagrams of crack distribution can furtherly prove it. (1) When beam 2\# fails, the cracks that appeared are relatively short and dense. The crack spacing and the average width of beam $2 \#$ is much smaller than that of beam 5\#. (2) The compressive strain exceeds 0.002 for beam 2\#, being 0.0008 for beam $5 \#$ when fails. Based
TABLE 7: Strain result of tensile side (measuring points 4-6\#) under normal loading.

\begin{tabular}{lcccc}
\hline Beam no. & $2 \#$ & $3 \#$ & $4 \#$ & $5 \#$ \\
\hline Strain/ $\mu \varepsilon$ & 140 & 163 & 196 & 285 \\
$Q_{f}(\%)$ & 100. & 85.9 & 71.4 & 49.1 \\
Residual strain $/ \mu \varepsilon$ & 0 & 3 & 7 & 17 \\
Relative residual strain $(\%)$ & 0 & 1.8 & 3.6 & 6 \\
\hline
\end{tabular}

on the above two reasons, the failure mode of beams 2 5\# gradually changed from ductile failure to brittle failure.

\subsection{Strain Analysis}

4.2.1. Normal Load Strain. The normal loading strain results are shown in Tables 7 and 8 and Figures 12 and 13. From the figure, at the preliminary stage of loading (when the total loading weight is less than $7 t$ ), the strain-load relationship is linear. The tensile test concrete strain-load curve is obviously nonlinear when loading weight is bigger than $7 t$, indicating that invisible microcracks on the tensile side will gradually appear at the middle and late loading process. At the last loading process, when the total loading weight is $32.2 t$, the strain on the tension side of beams $2 \#, 3 \#, 4 \#$, and $5 \#$ gradually increases. In other words, the strength of beams $2 \#, 3 \#, 4 \#$, and $5 \#$ decrease in sequence. After unloading, the residual strains of all selected beams are less than $20 \%$.

In a hollow slab beam fire, the concrete strength of the hollow slab section will degrade accordingly. For simplicity, this phenomenon is referred to as the overfire degradation strength in later parts of this article. As mentioned before, beam $2 \#$ is the reference beam, and its concrete strength can be regarded as the benchmark. Thus, relative overfire-degradation strength $\left(Q_{f}\right)$ can be defined by the following formula:

$$
Q_{f}=\frac{\varepsilon_{0}}{\varepsilon_{i}} .
$$

$\mathrm{n}$ the formula, $\varepsilon_{0}$ is the midspan deflection of the unfired beam and $\varepsilon_{i}$ is the midspan deflection of beam i\# under the same load.

From Table 8, when the maximum total load under normal loading is $32 t$, the corresponding maximum bending moment of the pure bending section in the midspan is $1906 \mathrm{kN} \mathrm{m}$. And the design value of ultimate bending moment of this section has been reached. The relative overfire degradation strength $Q_{f}$ of beams 3\#, 4\#, and 5\# is, respectively, $85.7 \%, 71.5 \%$, and $49.1 \%$. Considering the increase of the tensile strain caused by the concrete microcracks during the later loading process, this value of the corresponding beam is less than the relative degradation stiffness after being exposed to fire $K_{f}$.

4.2.2. Ultimate Load Strain. The compressive strain results of each beam at the end condition of the ultimate loading process are shown in Table 9. In ultimate failure, the compressive strain on the compression side of beams $2 \#$ and $3 \#$ exceeds 0.002 , while the compressive strain of beam 5\#, which was most seriously damaged by the fire, was only 
TABLE 8: Tensile strain measurements under normal loading (32.2t).

\begin{tabular}{|c|c|c|c|c|c|}
\hline \multirow{2}{*}{ Measuring point } & \multirow{2}{*}{ Bridge deck position } & \multicolumn{4}{|c|}{ Strain for the point $/ \mu \varepsilon$} \\
\hline & & Beam 2\# & Beam 3\# & Beam 4\# & Beam 5\# \\
\hline $1-6 \#$ & One-eighth of the span & 40 & 50 & 60 & 96.4 \\
\hline $2-6 \#$ & Quarter of the span & 48 & 59 & 73 & 119.5 \\
\hline $3-6 \#$ & Three-eighths of the span & 117 & 126 & 138 & 161.9 \\
\hline $4-6 \#$ & A half of the span & 140 & 182 & 226 & 284.5 \\
\hline $5-6 \#$ & Five-eighths of the span & 122 & 128 & 139 & 185.4 \\
\hline $6-6 \#$ & Three-fourths of the span & 51 & 62 & 77 & 129.8 \\
\hline $7-6 \#$ & Seven-eighths of the span & 42 & 51 & 63 & 69.7 \\
\hline
\end{tabular}

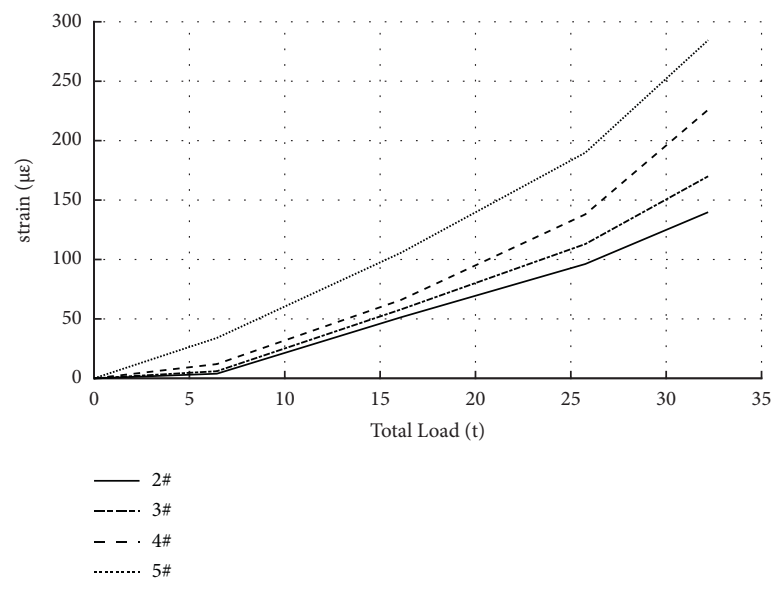

FIGURE 12: Strain history of normal loading tension side (measuring points 4-6\#).

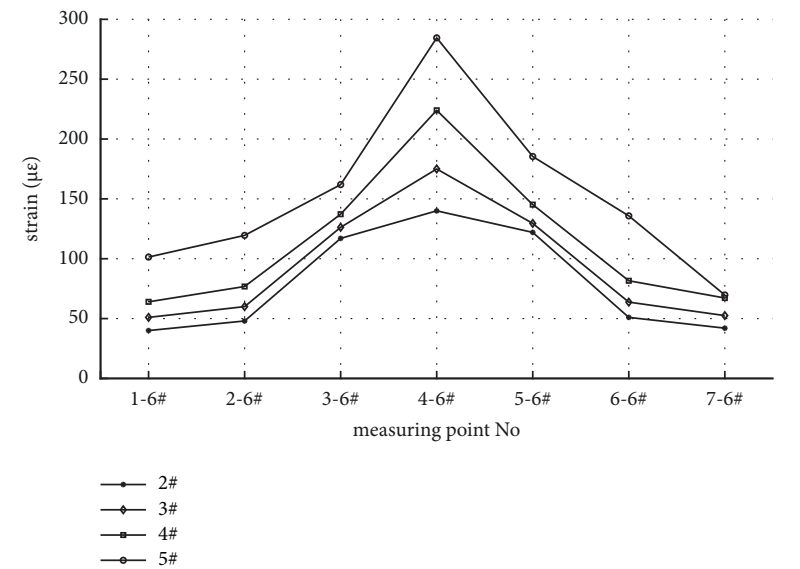

FIGURE 13: Strain distribution diagram of each section (tensile side).

$814 \mu \varepsilon$. And the strength of concrete materials is far from being fully utilized. The strain loading history of concrete on the compression side of a typical beam is shown in Figure 14.

\subsection{Fracture Development Analysis}

4.3.1. Crack Development under Normal Loading. During the normal loading process, no visible cracks appear in the beam bodies.
TABLE 9: Stress and strain measurements under ultimate loading.

\begin{tabular}{lcccc}
\hline Beam no. & $2 \#$ & $3 \#$ & $4 \#$ & $5 \#$ \\
\hline Compressive strain/ $\mu \varepsilon$ & 2021 & 1843 & 1429 & 814 \\
\hline
\end{tabular}

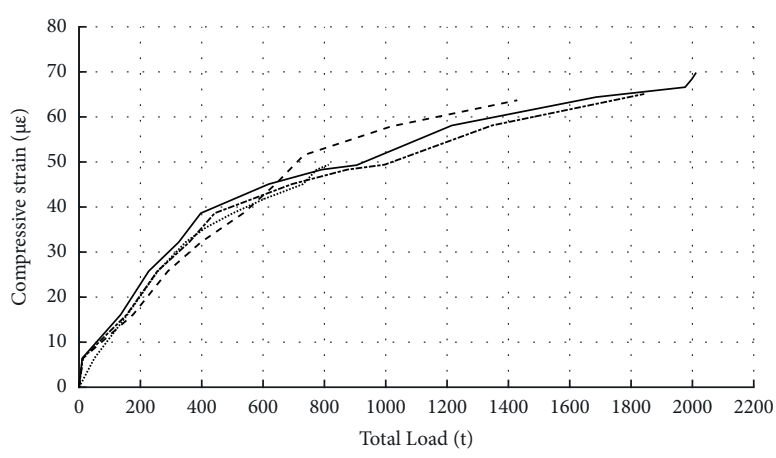

$$
\begin{gathered}
-2 \# \\
---.3 \# \\
--.4 \# \\
\ldots . . . . .5 \#
\end{gathered}
$$

Figure 14: Strain distribution of typical beam section (tension side).

4.3.2. Crack Development under Ultimate Loading. Check Table 10 for the loading force when visible cracks occurred in the beam body. When visible cracks appear, the loading tonnage of beams 2\#, 3\#, 4\#, and 5\# decreases sequentially. Several reasons are shown as follows: (1) The bridge bottom plates are directly burned when caught fire, resulting in the 
TABLE 10: Loads of beams with visible cracks.

\begin{tabular}{lcc}
\hline No. & Load tonnage when cracked $/ t$ & Remarks \\
\hline Beam 2\# & 48.3 & - \\
Beam 3\# & 46.8 & - \\
Beam 4\# & 45.1 & The floor starts to seep \\
Beam 5\# & 38.6 & Unusual noise from the steel strand \\
\hline
\end{tabular}

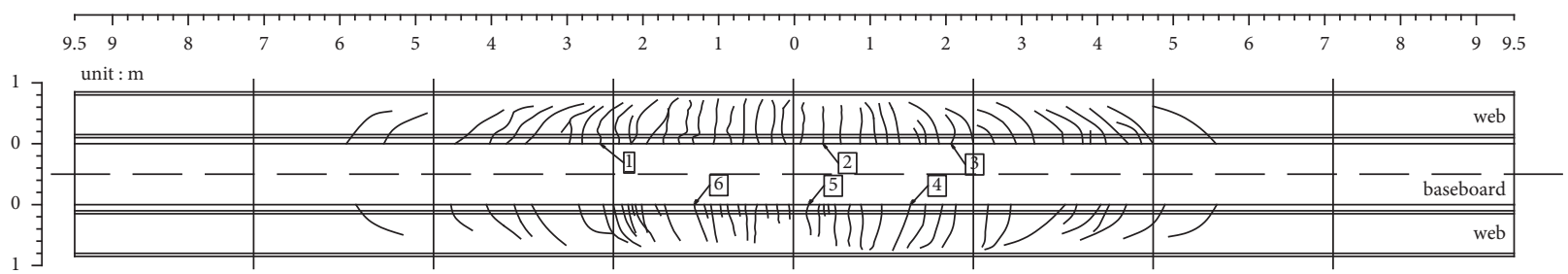

(a)

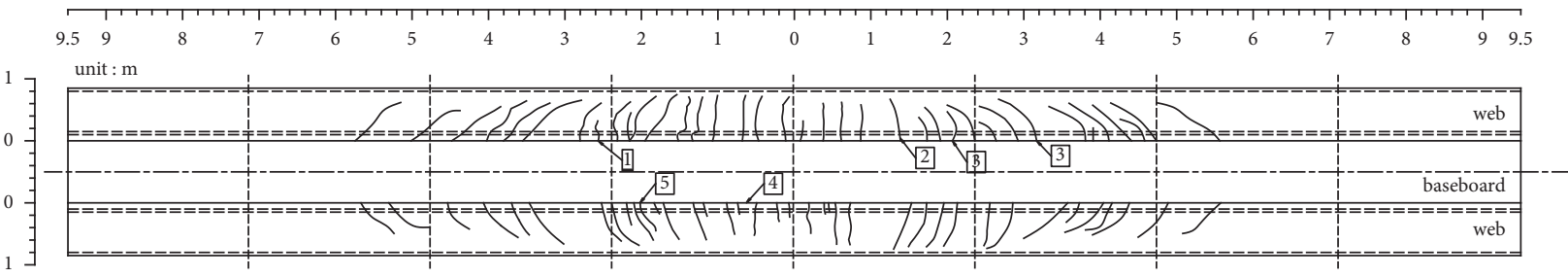

(b)

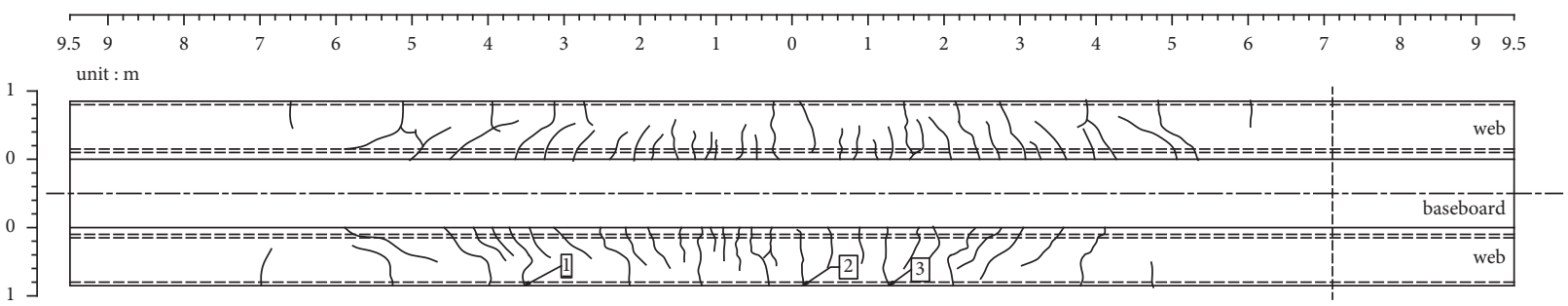

(c)

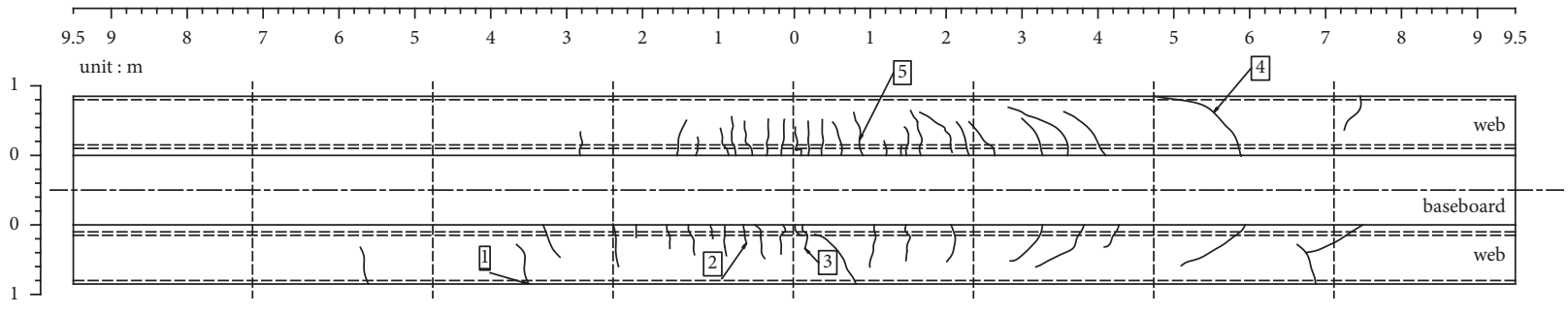

(d)

FIgURE 15: Schematic diagram of cracks at the end of limit loading. (a) Beam 2\#. (b) Beam 3\#. (c) Beam 4\#. (d) Beam 5\#.

loss of effective prestress and the reduction of the decompression moment. (2) The tensile performance of concrete will decrease after cooling when the overfire temperature exceeds $300^{\circ} \mathrm{C}$. (3) Other reasons, such as the reduction of the bonding strength between the steel bar and the concrete, will also cause the bending moment to decrease for the beams and slabs after being exposed to fire reduce.

After the ultimate load is terminated, the cracks of the test beam are shown in Figure 15. When the ultimate failure occurs, the average cracks' spacing of the $2 \#, 3 \#, 4 \#$, and 5\# beam webs increases successively. And the proportion of long and wide cracks increases. The average crack spacing of beam $5 \#$ is about two times the distance of beam $2 \#$ when destroyed.

\section{Conclusion}

In this paper, the appearance inspection and classification of prestressed concrete thin slab beams removed after a fire in an operating expressway are carried out. On this basis, four typical full-scale beams are selected for flexural failure test research. And the regular patterns of the mechanical properties of such thin-slab beams after a bridge fire are obtained. To a certain extent, these results make up for the 
insufficiency of the numerical calculation method of thermal field coupling, and the following conclusions were initially obtained:

(1) The drop-off depth and area of concrete after exposure to fire can be used as the characteristic parameters for the rapid identification of the bottom surface from prestressed concrete thin-slab beams after a bridge fire.

(2) Brittle failure is the main mode of beams that slab concrete falling off in $97 \%$ area with a characteristic depth more than $2.6 \mathrm{~cm}$ on the bottom surface when directly exposed to fire. Thus, it is not appropriate to use thin-slab beams for busy road networks transporting hazardous chemicals.

(3) Prestress loss will cause height reduction of the concrete shear zone, which is one of the main reasons why the bending-shearing failure of such beams happened before the pure bending failure.

(4) Only the bottom surface of the hollow slab is directly exposed to the fire in this study. Thus, when the typical depth of the concrete spalling of the bottom plate after a fire is close to the net protective layer of the steel strand, the flexural bearing capacity is only $76 \%$ of that before the fire.

(5) The mechanical properties of the prestressed concrete thin-slab beams whose bottom plate and web are simultaneously burned at high temperatures need further studies.

\section{Data Availability}

Some or all data, models, or code that support the findings of this study are available from the corresponding author upon reasonable request.

\section{Conflicts of Interest}

The authors declare that they have no conflicts of interest regarding the publication of this paper.

\section{Acknowledgments}

Financial support from Transportation Science and Technology Project of Shandong Province (Grant no. 2017B62) was gratefully acknowledged by the first and the second authors, respectively.

\section{References}

[1] Ke Zhang, Numerical Simulation Analysis of Fire Cracking of concrete Beam Bridge, Chongqing Jiaotong University, Chongqing, China, 2018, in Chinese.

[2] H. He, The Experiment of Monolithic Reinforcement for Hollow Slab of Reinforced Concrete, Chongqing Jiaotong University, Chongqing, China, 2013, in Chinese.

[3] W. Z. Zheng, X. M. Hou, D. S. Shi, and M. X. Xu, "Experimental study on concrete spalling in prestressed slabs subjected to fire," Fire Safety Journal, vol. 45, no. 5, pp. 283-297, 2010.
[4] J. Wang, Y. Cai, and D. Huang, "Testing research on thermal creep strain model of prestressing tendons and application of FEM analysis," China Civil Engineering Journal, vol. 32, no. 11, pp. 1-5, 2004, in Chinese.

[5] Y. Ding, W. Zhang, X. Han, and X. Shi, "Study on the temperature field of prestressed concrete beam-plate in underbridge fire hazard and the prestress loss of tendon," China Civil Engineering Journal, vol. 48, no. S1, pp. 42-47, 2015.

[6] M. B. Dwaikat and V. K. R. Kodur, "Hydrothermal model for predicting fire-induced spalling in concrete structural systems," Fire Safety Journal, vol. 44, no. 3, pp. 425-434, 2009.

[7] V. K. R. Kodur and M. Dwaikat, "A numerical model for predicting the fire resistance of reinforced concrete beams," Cement and Concrete Composites, vol. 30, no. 5, pp. 431-443, 2008.

[8] S.-H. Yun and J.-S. Jeon, "Post-fire damage assessment of Korean bridges using thermal-structure interaction fire analysis," Magazine of Concrete Research, vol. 70, no. 18, pp. 938-953, 2018.

[9] G. Zhang, M. Zhu, S. He, and C. J. Wang, "Failure model analysis of prestressed concrete girder exposed to fire," China Journal of Highway and Transport, vol. 30, no. 2, pp. 77-85, 2017.

[10] N. Yanagisawa, Y. Imagawa, O. Ohyama, M. Rutner, and A. Kurita, "Fire safety of bridges-methodology supporting design and forensic evaluation," Steel Construction, vol. 10, no. 1, pp. 2-9, 2017.

[11] P. R. Prakash and G. Srivastava, "Nonlinear analysis of reinforced concrete plane frames exposed to fire using direct stiffness method," Advances in Structural Engineering, vol. 21, no. 7, pp. 1036-1050, 2018.

[12] J. Alos-Moya, I. Paya-Zaforteza, A. Hospitaler, and E. L. Ossori, "Valencia bridge fire tests: validation of simplified and advanced numerical approaches to model bridge fire scenarios," Advances in Engineering Software, vol. 128, pp. 55-68, 2018.

[13] E. Beneberu and N. Yazdani, "Residual strength of CFRP strengthened prestressed concrete bridge girders after hydrocarbon fire exposure," Engineering Structures, vol. 184, no. APR.1, pp. 1-14, 2019.

[14] G. Zhang, V. Kodur, W. Yao, and Q. Huang, "Behavior of composite box bridge girders under localized fire exposure conditions," Structural Engineering \& Mechanics, vol. 69, no. 2, pp. 193-204, 2019.

[15] H. Chaowei, L. Kang, L. Hongyin, and W. Laiyong, "Research on the material properties of prestressed concrete girder bridge after exposed to fire," IOP Conference Series: Earth and Environmental Science, vol. 371, no. 4, Article ID 042027, 2019.

[16] China Communication Press, Jtj D62-2004 Code for Design of Highway Reinforced Concrete and Prestressed Concrete Bridges and Culverts, China Communication Press, Beijing, China, 2004, In Chinese.

[17] China Communication Press, Jgj/T J21-2011 Specification for Inspection Andevaluation of Load-Bearing Capacity of Highway Brides, Communnications Press of China, Beijing, China, 2014, in Chinese.

[18] China Communication Press, Cecs 252:2009, Standard for Building Structural Assessment after the Fire, Planning Press of China, Beijing, China, (in Chinese), 2009.

[19] S.-A. Li, Mechanical Performance Process and post-disaster Evaluation Method of Pre-stressed concrete Girder Bridg, Chang'an University, Xian, China, 2012. 
[20] M. F. Day, E. A. Jenkinson, and A. I. Smith, "Effect of elevated temperatures on high-tensile-steel wires for prestressed concrete," Proceedings Instituting of civil Engineers, vol. 16, no. 5, pp. 55-70, 1960.

[21] C. T. Davie, H. L. Zhang, and A. Gibson, "Investigation of a continuum damage model as an indicator for the prediction of spalling in fire exposed concrete," Computers \& Structures, vol. 94-95, no. 3, pp. 54-69, 2012.

[22] J. D. Glassman and M. E. M. Garlock, "High temperatures and bridges: transverse stiffeners in steel girder fire performance," Bridge Structures, vol. 10, no. 1, pp. 43-52, 2014.

[23] T. Liu, Study on Decay Mechanism of Effective Prestress of concrete Bridges Exposed to fire, Chang'an University, Xian, China, 2016, in Chinese. 